\title{
Front-Face Fluorescence Using UV-LED Coupled to USB Spectrometer to Discriminate between Virgin Olive Oil from Two Cultivars
}

\author{
Gilbert Yvon Mbesse Kongbonga ${ }^{1,2,3 *}$, Kaouther Ben Hassine ${ }^{4,5,6,7}$, Hassen Ghalila ${ }^{2}$, \\ Dhafer Malouche ${ }^{8}$
}

${ }^{1}$ Faculty of Science, University of Bangui, Bangui, Central African Republic

${ }^{2}$ Laboratoire de Spectroscopie Atomique Moléculaire et Applications (LSAMA), Faculty of Sciences, University of Tunis El Manar, Tunis, Tunisia

${ }^{3}$ Centre for Atomic Molecular Physics and Quantum Optics (CEPAMOQ), Faculty of Science, University of Douala,

Douala, Cameroon

${ }^{4}$ Laboratory of Biochemistry, UR: Human Nutrition and Metabolic Disorder, Faculty of Medicine, Monastir, Tunisia

${ }^{5}$ Institut de l'Olivier Unité Technologie et Qualité, Sfax, Tunisia

${ }^{6}$ National Institute for Applied Sciences and Technologies, Tunis, Tunisia

${ }^{7}$ Higher School of Agriculture of Mograne, Mograne, Tunisia

${ }^{8}$ Engineering School of Statistics and Information Analysis, University of Carthage, Tunis, Tunisia

Email: ${ }^{\star}$ yvonmbesse@yahoo.fr

How to cite this paper: Kongbonga, G.Y.M., Ben Hassine, K., Ghalila, H. and Malouche, D. (2019) Front-Face Fluorescence Using UV-LED Coupled to USB Spectrometer to Discriminate between Virgin Olive Oil from Two Cultivars. Food and Nutrition Sciences, 10, 119-127.

https://doi.org/10.4236/fns.2019.102010

Received: November 25, 2018

Accepted: January 30, 2019

Published: February 2, 2019

Copyright $\odot 2019$ by author(s) and Scientific Research Publishing Inc. This work is licensed under the Creative Commons Attribution International License (CC BY 4.0).

http://creativecommons.org/licenses/by/4.0/

\begin{abstract}
A simple setup using a $365 \mathrm{~nm}$ LED coupled to a USB spectrometer through an optical fibre, in a front-face fluorescence configuration, was used to investigate the ability of fluorescence spectroscopy technique to discriminate between varieties of olive oil. To achieve this task, Virgin Olive Oils (VOO) from two major Tunisian olive cultivars known as Chetoui and Chemlali were used. Spectral analysis showed a clear separation between these two VOO varieties. A one-way ANOVA attests that this discrimination is significant. The Principal Components Analyses (PCA) showed that the normalized fluorescence intensities are the good parameters for this discrimination. This observation strengthens the potential of our spectral parameters to perform reliable analysis.
\end{abstract}

\section{Keywords}

Chemometrics, Fluorometry, Oils, Olive Oil, PCA, UV/Visible

\section{Introduction}

The qualitative and quantitative difference between olive oils are mainly due to the specific characteristics of cultivars used [1]. Rightness of analyses which lead 
to accurate authentication of olive oil constitutes one of the major challenges in the industry of olive oil since the demand of olive oils is increasing and there is a growing commercial interest in high quality products.

Tunisia is well known for the high quality of its olive oil. This industry depends mainly on two cultivars namely the "Chetoui" which grows in the mountainous regions and the "Chemlali" which is prevalent in the central semi-arid regions and southern arid regions of the country [2] [3]. These two cultivars represent $95 \%$ of the plantations and contribute to more than $80 \%$ of the national production of olive oil [2].

The Chemlali cultivars cover $2 / 3$ of the plantations and represent approximately $60 \%$ of national production of olive oil [2] [3] [4]. The lack of water in arid zones has a negative impact on their quality. However, despite these shortcomings, most of the Chemlali cultivars have ordinary organoleptic composition and a very characteristic taste with high levels of palmitic acids [4] [5]. The Chetoui cultivar represents about $20 \%$ of national production [6]. Several studies have shown that this cultivar has a great capacity to adapt to various climatic conditions [5] [6]. The Chetoui cultivar is also known for the quality of its oil that is characterized by a high antioxidants rate and a high proportion of oleic acids [5] [6]. In general, and regardless to the region and to the climatic conditions, the olive oil produced from the Chetoui cultivar has a high oxidative stability and high anti-radical activity compared to the Chemlali cultivar [7].

Indeed, several analytical techniques have been proposed and are used for qualitative and quantitative analyses of olive oils [8]. Most of these techniques are often very expensive and rather laborious to achieve.

Recently, fluorescence spectroscopy has become an emerging analytical technique, due to its high sensitivity and simplicity and requires little or no sample preparation. Many works have been successfully applied for authentication of olive oil [9], for the detection of adulteration of olive oil [10] [11], for the characterization of olive oil [12] and for the analysis of oxidation of olive oil [13] [14] [15].

The aim of this work is to use the high sensitivity of fluorescence spectroscopy coupled to chemometric analyses to discriminate olive oil according to the cultivars with a very simple setup. This is done through its application to the two Tunisian Virgin Olive Oil (VOO) from cultivars Chetoui and Chemlali. The confrontations of these measures with another proven technique, such as Peroxide Value (PV) measures, strengthen and promote this technique for widest diffusion.

\section{Material and Methods}

The study was carried out on seventeen VOOs from two main Tunisian cultivars, namely Chetoui and Chemlali. VOO samples were collected in several regions during the same harvest. All samples were placed in amber glass bottles and stored in the dark. 


\subsection{Analytical Indices}

Analytical indices such as free acidity, peroxide value (PV) and UV absorbance at $232 \mathrm{~nm}$ and $270 \mathrm{~nm}\left(\mathrm{~K}_{232}\right.$ and $\left.\mathrm{K}_{270}\right)$ were determined according to the European Official Methods of Analysis [8].

\subsection{Fluorescence Spectroscopy}

We used the experimental setup described by Mbesse et al. [15]. A light emitting diode (LED) with an emission wavelength at $365 \mathrm{~nm}$, is used as the excitation source. The excitation light from the source is channelled to the sample through a Y-type optical fibre bundle. The fluorescence emission of the sample was captured by the same optical fibre bundle and goes to the Ocean Optics USB2000 spectrometer which was connected to a computer. The signal acquisition was controlled by the OOIBase 32 software. The emission wavelength range was set between $400 \mathrm{~nm}$ to $800 \mathrm{~nm}$. For the analysis, a quartz vat was filled by each sample and placed in front of the optical fibre.

To ensure the validity of the comparison between the different samples, each spectrum represented the average of 10 scans recorded after 100s of excitation. This lapse of time corresponds to the delay after which the intensity reaches a steady state. We used these parameters for all the samples in order to reproduce the measures in the same experimental conditions. Deconvolution of the fluorescence spectra was used to identify fluorophores. The data processing was made with the software Igor Pro 6.0.

\subsection{Chemometric Methods}

Analysis of variance (ANOVA) is applied to the data. The one-way ANOVA is used to show if there is significant difference between these two VOOs cultivar. In this analyze, the factor is the cultivar and the variables are the normalize intensities ( $\mathrm{R} \_1, \mathrm{R} \_2$ and $\mathrm{R} \_3$ defined further in the subsection 3.2.) and the analytical indices (PV, $\mathrm{K}_{232}, \mathrm{~K}_{270}$ and Acidity). A Principal Components Analysis (PCA) is also applied to both spectral data and physico-chemical parameters. The aim of PCA is to reduce the large number of parameters influencing the measures to a much smaller number of principal components (PCs) that capture the vast majority of variance in the data. This approach considerably reduces the dimensionality of the original data, enabling effective visualization, regression and classification of multivariate data [16]. For the PCA, samples were considered as individuals while the variables were the normalized fluorescence intensities (R_1, R_2, R_3), PV, $K_{232}, K_{270}$ and Acidity. PCA is used in this study to find the correlation that may exist between the set of variables. The statistical analysis is done using " $R$ " software.

\section{Results and Discussion}

\subsection{Analysis of Analytical Indices}

According to several analytical indices (Acidity, Peroxide Value, $\mathrm{K}_{232}, \mathrm{~K}_{270}$ ) es- 
tablished by the European standards VOOs are classified with respect to the quality of oil [8]. Table 1 shows the average on measurements of analytical indices for Chetoui samples and Chemlali samples.

For our samples, we noted that Acidity's values are less than $0.8 \%$ and then peroxide value (PV) measured is significantly lower than the threshold of 20 $\mathrm{meqO}_{2} / \mathrm{Kg}$ fixed for Extra Virgin Olive Oil (EVOO). We also observed that the absorbance at $232 \mathrm{~nm}$ and $270 \mathrm{~nm}\left(\mathrm{~K}_{232}\right.$ and $\left.\mathrm{K}_{270}\right)$ slightly exceeds the threshold established for EVOO. However, all the determined analytical indices values show that our samples involve standard characteristics of VOO and these values do not show significant difference between Chetoui and Chemlali cultivars of olive oil.

\subsection{Spectral Analysis}

Fluorescence spectra of all VOO samples are shown in Figure 1. We can clearly see a grouping of oil spectra according to their cultivars in the emission band between $400 \mathrm{~nm}$ and $600 \mathrm{~nm}$.

Vegetable oils are a complex mixture of several fluorescent molecules. Consequently, VOO spectrum shows several broad emission peaks. To highlight the main emission peaks, a deconvolution is performed for each fluorescence spectrum of VOO according to the method described in our previous works [17].

Table 1. Average of analytical indices for our sample.

\begin{tabular}{ccc}
\hline Analytical indices & Chetoui & Chemlali \\
\hline Acidity (\%) & $0.4 \pm 0.2$ & $0.5 \pm 0.2$ \\
$\mathrm{PV}\left(\mathrm{meq} \mathrm{O}^{2} / \mathrm{kg}\right)$ & $6.5 \pm 2.1$ & $5.1 \pm 4$ \\
$\mathrm{~K}_{232}$ & $2.25 \pm 0.38$ & $2.42 \pm 0.25$ \\
$\mathrm{~K}_{270}$ & $0.26 \pm 0.04$ & $0.28 \pm 0.04$ \\
\hline
\end{tabular}

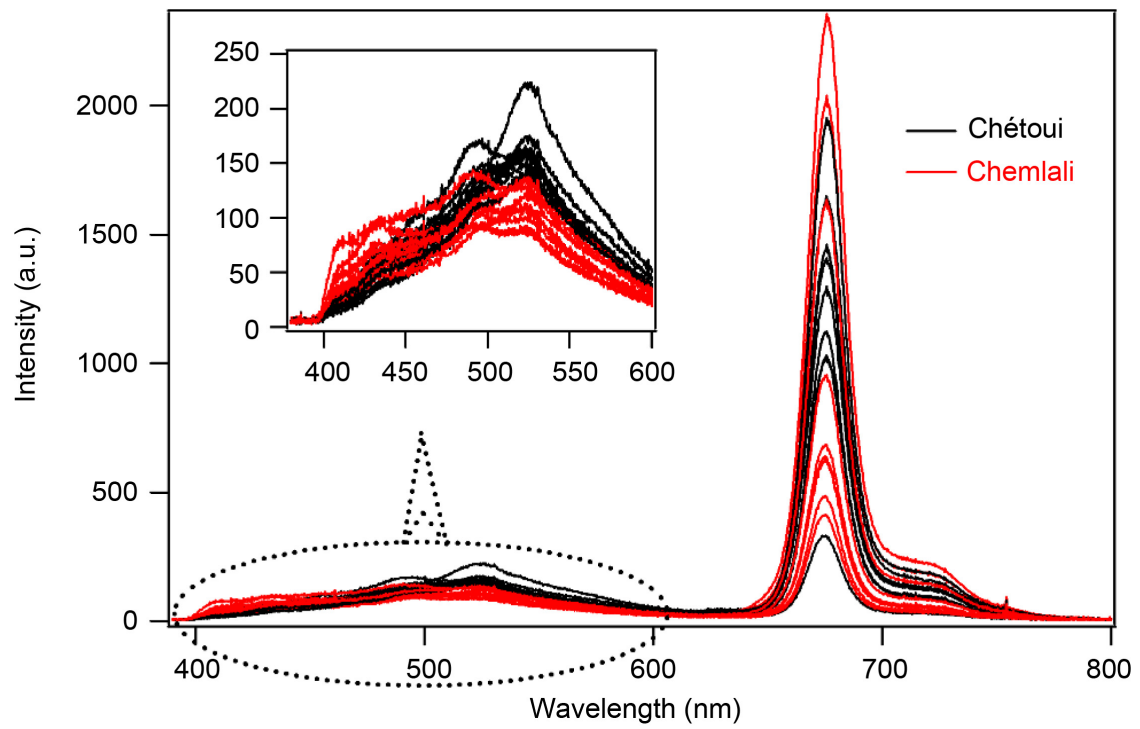

Figure 1. Superposition of oils spectra for all samples. 
Seven peaks were obtained at the emitting wavelength around $432 \mathrm{~nm}, 455 \mathrm{~nm}$, $489 \mathrm{~nm}, 524 \mathrm{~nm}, 565 \mathrm{~nm}, 680 \mathrm{~nm}$ and $730 \mathrm{~nm}$. The emission at $432 \mathrm{~nm}, 455 \mathrm{~nm}$ and $489 \mathrm{~nm}$ are assigned to oxidation products and the one around $524 \mathrm{~nm}$ is assigned to the vitamin E [11] [18]. The two intense peaks at $680 \mathrm{~nm}$ and 730 $\mathrm{nm}$ correspond to the emission of the chlorophylls [11] [18]. In the following we focus the analysis in the band located between $400 \mathrm{~nm}$ and $600 \mathrm{~nm}$.

From the deconvolution operation we determine the position and the intensities of the emission peaks [17]. The intensity of these peaks is characteristic of proportion of emitting compound. In order to compare the different spectra, we proceeded to the normalization of each spectrum according to the method used by Mbesse et al. [17]. In this method the intensity of the peaks around $432 \mathrm{~nm}$, $455 \mathrm{~nm}$ and $489 \mathrm{~nm}$ are divided by the intensity of the peaks of vitamin E at 524 $\mathrm{nm}$. We define at the same time three variables, namely $\mathrm{R} \_1, \mathrm{R} \_2$ and $\mathrm{R} \_3$ corresponding to the normalized intensities of the peaks at $432 \mathrm{~nm}, 455 \mathrm{~nm}$ and 489 $\mathrm{nm}$ respectively. Figure 2 shows the normalized intensities obtained by using method of deconvolution of spectrum for each sample. We can see clearly the grouping of the curves according to the variety of the oil.

The low normalized intensity means a low proportion of oxidation products compared to vitamin E. We can note that the VOO's Chetoui group has relatively a low normalized intensity compared to the VOO's Chemlali group. This observation is in agreement with the works of Issaoui et al. [7] who emphasizes that the Chetoui has high levels of antioxidant and high oxidative stability compared to the Chemlali.

\subsection{Chemometric Analysis}

It is important to know that each cultivar includes several samples and each sample is represented by the three normalized intensities (R_1, R_2 and $R \_3$ ) and the four analytical indices ( $\mathrm{PV}, \mathrm{K}_{232}, \mathrm{~K}_{270}$ and Acidity). The results of the

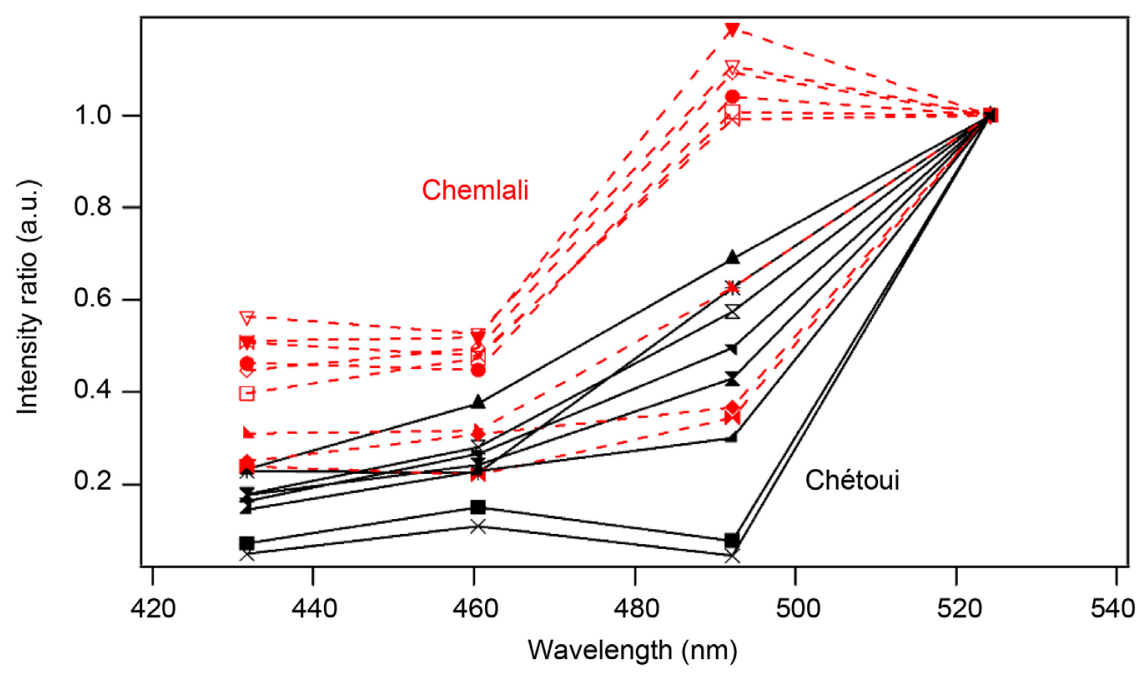

Figure 2. Intensity ratio of peaks around $432 \mathrm{~nm}, 455 \mathrm{~nm}$ and $489 \mathrm{~nm}$ to the peak of vitamin E (at $524 \mathrm{~nm}$ ). 
ANOVA performed on each variable are summarized in Table 2. We can see that the results of ANOVA for the PV, $\mathrm{K}_{232}, \mathrm{~K}_{270}$ and Acidity show clearly no difference between the cultivars groups. But the p-values obtained in the cases of spectral data are below the threshold $(\alpha=0.05)$. This means that the difference between the groups formed according to the VOO cultivar is significant. Several studies have shown the difference between these two VOO cultivars in terms of acidic composition and minor compound concentrations (phenolic compounds, vitamin E, etc.) [7] [19]. Here, this difference is observed directly from fluorescence spectrum analysis.

The peaks used to show the difference between the two cultivars are the peaks of oxidation products and the peak of antioxidants. A PCA is performed on all data (spectral data and analytical indices data). The goal is to find potential correlations between variables and to show which variables that most contribute in the principal components. Like this we can find the good parameters for this discrimination. Figure 3 presents PCA results and shows that all the variables are well represented by the two first principal components (PCs) that account for $73 \%$. We obtain on the individuals factor map (Figure 3(a)) a clear separation between Chetoui and Chemlali as that observed on the Figure 1 and Figure 2.

The variables factor map (Figure 3(b)) shows that all the variables, except variable "Acidity", are well represented in the correlation circle. The discrimination between Chetoui and Chemlali observed in individual factor map (Figure 3(a)) is mostly due to PC1. Regarding to the high correlation of $\mathrm{R} \_1, \mathrm{R} \_2$ and R_3 with PC1 in Figure 3(b), we can confirm that the spectral variables are the good parameters of this discrimination. We observe a correlation (inversely correlated) between all spectral variables and peroxide value (PV). It is worthy to recall here that peroxide value measures the quantity of hydroperoxides present in VOO. So, the weak normalized intensities of the peaks of oxidation products of Chetoui in Figure 2 and the correlation between R_1, R_2, R_3 and PV shows the high antioxidant content and the high oxidative stability of the Chetoui cultivar compared to the Chemlali cultivar. This correlation encourages us to use these spectral parameters to make more complete analysis of VOOs.

Table 2. Results of ANOVA test ( $\alpha=0.05$ ) performed for each variable.

\begin{tabular}{ccc}
\hline & p-value & Interpretation \\
\hline Acidity & 0.47500 & No significant difference \\
PV & 0.13450 & No significant difference \\
$\mathrm{K}_{232}$ & 0.53060 & No significant difference \\
$\mathrm{K}_{270}$ & 0.65770 & No significant difference \\
$\mathrm{R} 1$ & 0.00004 & Significant difference \\
$\mathrm{R} 2$ & 0.00100 & Significant difference \\
$\mathrm{R} 3$ & 0.01700 & Significant difference \\
\hline
\end{tabular}




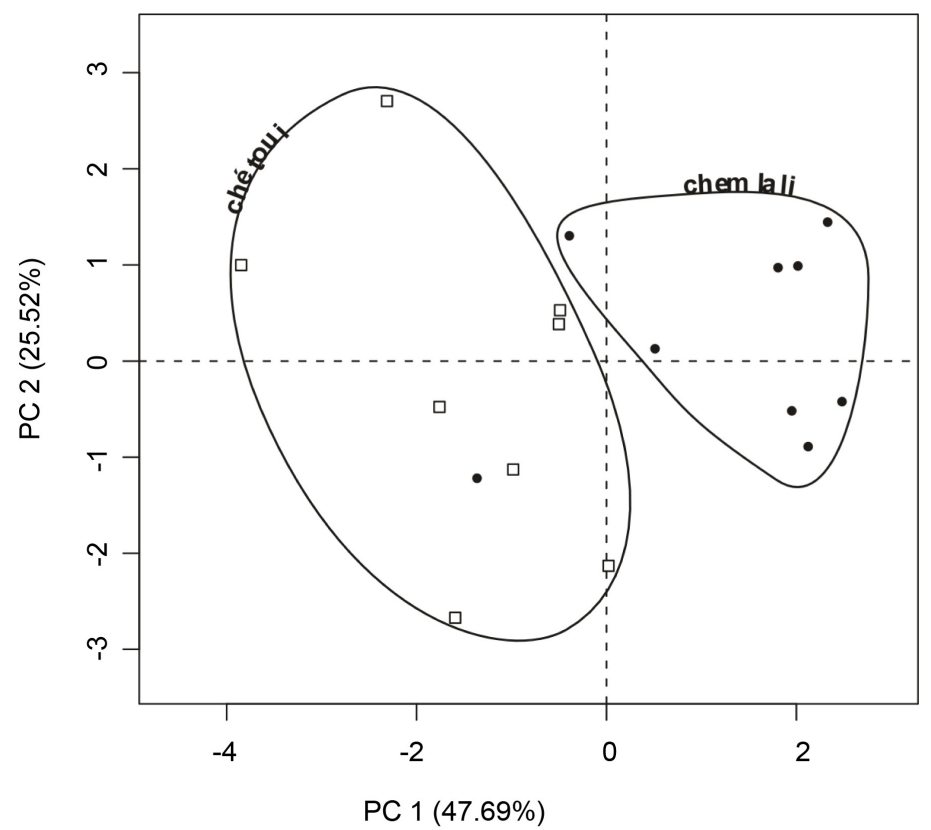

(a)

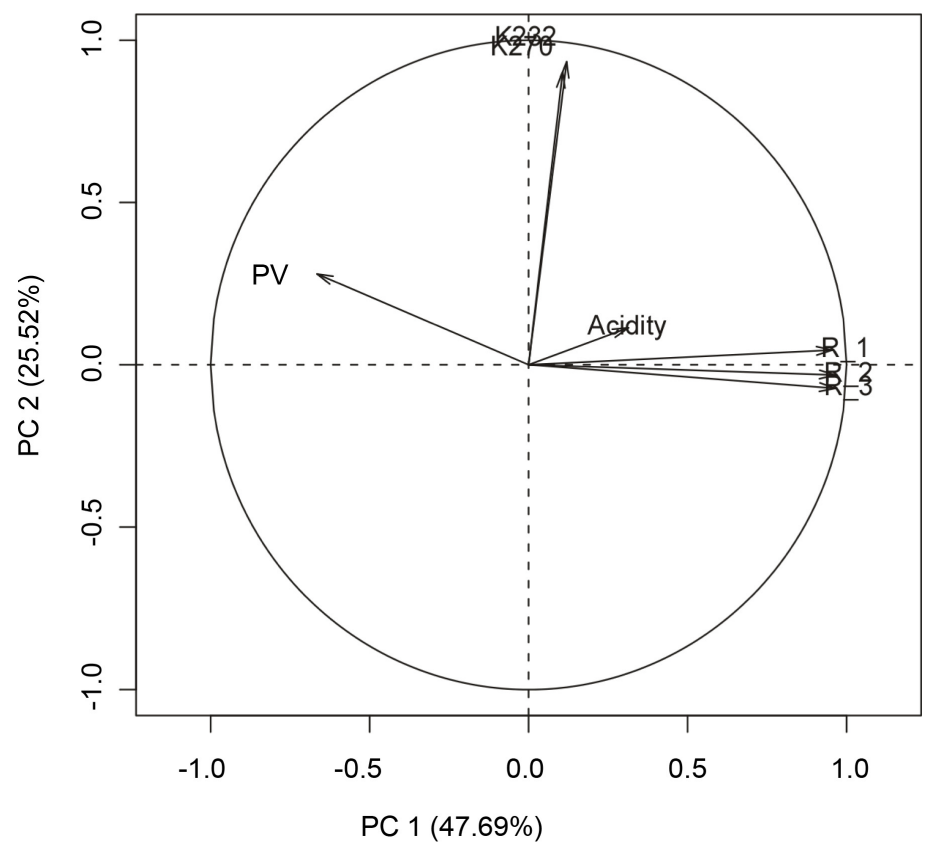

(b)

Figure 3. PCA results. (a) Individuals factor map (PCA) showing discrimination between chétoui and chemlali; (b) Variables factor map showing an inverse correlation between the Peroxide Value (PV) and the oxidation products ( $\left.\_\_1, R \_2, R \_3\right)$.

\section{Conclusion}

Due to the high sensibility and ease of use (very simple setup), fluorescence spectroscopy presents itself as a suitable technique for the analysis of olive oils and quality control. We have, based on the fluorescence spectra, and observed a small difference between the two cultivars Chetoui and Chemlali. The analysis of 
variance (ANOVA) shows that this difference is significant $(\mathrm{p}<0.05)$. This first result proves the ability of the fluorescence technique to quickly identify special variety of oil among others with the help of simple established spectral parameters (R_1, R_2 and R_3). Secondly, the Principal Components Analysis (PCA) emphasized the existence of correlation between Peroxide Value (PV) and spectral variables. This correlation points out the high oxidative stability of Chetoui compare to Chemlali. All of our results can lead to a new kind of analysis because it gives the possibility to use this technique to investigate oil's stability and quality control.

\section{Acknowledgements}

The authors are grateful to the Abdus Salam International Centre for Theoretical Physics (Italy) for financial support through affiliated center of Tunisia and NET-45 projects. They also acknowledge Professor Grati-Kammoun Naziha and Professor Hammami Mohamed for helpful contribution.

\section{Conflicts of Interest}

The authors declare no conflicts of interest regarding the publication of this paper.

\section{References}

[1] Hannachi, H., Breton, C., Msallem, M., Ben El Hadj, S., El Gazzah, M. and Bervillé, A. (2008) Differences between Native and Introduced Olive Cultivars as Revealed by Morphology of Drupes, Oil Composition and SSR Polymorphisms: A Case Study in Tunisia. Scientia Horticulturae, 116, 280-290. https://doi.org/10.1016/j.scienta.2008.01.004

[2] Issaoui, M., Flamini, G., Chehab, H., Luigi Cioni, P., Braham, M. and Hammami, M. (2011) Irrigation Regimes and Growing Area Effects on Chetoui Olive Oil Quality. Journal of Food Biochemistry, 37, 185-192. https://doi.org/10.1111/j.1745-4514.2011.00623.x

[3] Taamalli, A., Gomez-Caravaca, A.M., Zarrouk, M., Segura-Carretero, A. and Fernandez-Gutiérrez, A. (2010) Determination of Apolar and Polar Compounds and Other Chemical Parameters for the Discrimination of Six Different Varieties of Tunisian Extra-Virgin Olive Oil Cultivated in Their Traditional Area. European Food Research and Technology, 231, 965-975. https://doi.org/10.1007/s00217-010-1350-3

[4] Dabbou, S., Rjiba, I., Nakbi, A., Gazzah, N., Issoui, M. and Hammami, M. (2010) Composition Quality of Olive Oils from Cultivars Introduced in Tunisian Arid Zones in Comparison to Chemlali Cultivars. Scientia Horticulturae, 124, 122-127. https://doi.org/10.1016/j.scienta.2009.12.017

[5] Dabbou, S., Issoui, M., Servili, M., Taticchi, A., Sifi, S., Montedoro, G.F. and Hammami, M. (2009) Characterisation of Virgin Olive Oils from European Olive Cultivars Introduced in Tunisia. European Journal of Lipid Science and Technology, 111, 392-401. https://doi.org/10.1002/ejlt.200800032

[6] Ben Temine, S., Compeol, E., Cioni, P.L., Daoud, D. and Zarouk, M. (2006) Volatile Compounds from Chetoui Olive Oil and Variations Induced by Growing Area. Food Chemistry, 99, 315-325. https://doi.org/10.1016/j.foodchem.2005.07.046 
[7] Issaoui, M., Flamini, G., Brahmi, F., Dabbou, S., Ben Hassine, K., Taamali, A., Chehab, H., Ellouz, M. and Zarrouk, M. (2010) Effect of the Growing Area Conditions on Differentiation between Chemlali and Chetoui Olive Oils. Food Chemistry, 119, 220-225. https://doi.org/10.1016/j.foodchem.2009.06.012

[8] IOOC/T.15/NC No. 3/Rev.2 (2006) International Olive Council, Trade Standard Applying to Olive Oils and Olive-Pomace Oils.

[9] Guimet, F., Boqué, R. and Ferré, J. (2005) Study of Oils from the Protected Denomination of Origin "Siurana” Using Excitation-Emission Fluorescence Spectroscopy and Three-Way Methods of Analysis. Grasas y Aceites, 4, 292-297.

[10] Guimet, F., Boqué, R. and Ferré, J. (2004) Rapid Detection of Olive-Pomace Oil Adulteration in Extra Virgin Olive Oils from the Protected Denomination of Origin Siurana Using Excitation-Emission Fluorescence Spectroscopy and Three-Way Methods of Analysis. Analytica Chimica Acta, 52, 6673-6679.

[11] Sayago, A., Morales, M.T. and Aparicio, R. (2004) Detection of Hazelnut Oil in Virgin Olive Oil by a Spectrofluorimetric Method. European Food Research and Technology, 218, 480-483. https://doi.org/10.1007/s00217-004-0874-9

[12] Sikorska, E., Romaniuk, A., Khmelinskii, I.V., Herance, R., Bourdelande, J.L., Sikorski, M. and Koziol, J. (2004) Characterization of Edible Oils Using Total Luminescence Spectroscopy. Journal of Fluorescence, 14, 25-35.

https://doi.org/10.1023/B:JOFL.0000014656.75245.62

[13] Engelsen, S.B. (1997) Explorative Spectrometric Evaluations of Oil Deterioration. Journal of the American Oil Chemists Society, 74, 1495-1508. https://doi.org/10.1007/s11746-997-0068-2

[14] Cheikhousman, R., Zude, M., Bouve-Resse, D.J.-R., Léger, C.L., Rutledge D.N. and Birlouez-Aragon, I. (2005) Fluorescence Spectroscopy for Monitoring Deterioration of Extra Virgin Olive Oil during Heating. Analytical and Bioanalytical Chemistry, 382, 1438-1443. https://doi.org/10.1007/s00216-005-3286-1

[15] Mbesse Kongbonga, Y.G., Ghalila, H., Majdi, Y., Mbogning Feudjio, W. and Ben Lakhdar, Z. (2015) Investigation of Heat-Induced Degradation of Virgin Olive Oil Using Front Face Fluorescence Spectroscopy and Chemometric Analysis. Journal of the American Oil Chemists' Society. https://doi.org/10.1007/s11746-015-2704-6

[16] Brereton, R.G. (1992) Multivariate Pattern Recognition in Chemometrics, Illustrated by Case Studies. Elsevier Science, Amsterdam. https://doi.org/10.4236/fns.2011.27095

[17] Mbesse Kongbonga, Y.G., Ghalila, H., Boyomo Onana, M., Majdi, Y., Ben Lakhdar, Z., Mezlini, O. and Sevestre-Ghalila, S. (2011) Characterization of Vegetable Oils by Fluorescence Spectroscopy. Food and Nutrition Sciences, 2, 692-699.

[18] Kyriakidis, N.B. and Skarkalis, P. (2000) Fluorescence Spectra Measurement of Olive Oil and Other Vegetable Oils. Journal of AOAC International, 83, 1435-1439.

[19] Aouidi, F., Dupuy, N., Artaud, J., Roussos, S., Msallem, M., Perraud-Gaime, I. and Hamdi, M. (2012) Discrimination of Five Tunisian Cultivars by Mid InfraRed Spectroscopy Combined with Chemometric Analyses of Olive Olea europaea Leaves. Food Chemistry, 131, 360-366. https://doi.org/10.1016/j.foodchem.2011.08.041 